\title{
MERCOSUL E COOPERAÇÃO JURÍDICA INTERNACIONAL: UM SISTEMA PROCESSUAL ESTRATÉGICO À INTEGRAÇÃO.
}

\section{MERCOSUR AND INTERNATIONAL LEGAL COOPERATION: A STRATEGIC PROCESS SYSTEM FOR INTEGRATION}

Geziela Iensue

Doutora pela Universidade Federal do Paraná - UFPR. Pesquisadora bolsista do CNPq/ FUNDECT vinculada ao Mestrado em Direitos Humanos da Fundação Universidade Federal de Mato Grosso do Sul (UFMS). Professora Voluntária da Universidade Federal de Mato Grosso do Sul (UFMS). Mestre em Ciências Sociais Aplicadas pela Universidade Estadual de Ponta Grossa - UEPG (PR). Coordenadora do projeto de pesquisa "Migração, Direitos Humanos e Cooperação Jurídica Internacional nas fronteiras de Mato Grosso do Sul”(CNPq/FUNDECT). E-mail: igeziela@gmail.com

\section{Luciani Coimbra de Carvalho}

Doutora em Direito pela Pontifícia Universidade Católica de São Paulo. Mestre em Direito pela Pontifícia Universidade Católica de São Paulo. Professora Adjunta da Universidade

Federal de Mato Grosso do Sul. Professora do mestrado profissional PROFIAP e do mestrado acadêmico em direito da UFMS. Advogada (OAB/MS). Supervisora do projeto de pesquisa "Migração, Direitos Humanos e Cooperação Jurídica Internacional nas fronteiras de Mato Grosso do Sul” (CNPq/FUNDECT). E-mail: luciani.carvalho@ufms.br

Recebido em: 12/12/2016

Aprovado em: 30/01/2017

Doi: $10.5585 /$ rdb.v16i7.561

RESUMO: A temática da cooperação jurídica internacional suscita questões complexas, cujas lacunas e incertezas impõem e demandam respostas em construção. Devido ao aumento de atividades que transcendem as fronteiras políticas houve um impulso no que tange à cooperação jurídica entre os países. O presente artigo se propõe a examinar o desenvolvimento do instituto da cooperação jurídica internacional no âmbito do MERCOSUL com vistas a destacar o seu caráter instrumental e nevrálgico à consolidação do processo de integração no âmbito desse bloco regional. Para tanto, apresenta o instituto da cooperação jurídica internacional a partir de seus delineamentos, de suas finalidades, e de sua principiologia própria. Destaca a natureza da cooperação jurídica na contemporaneidade como um imperativo de direito e não como uma mera cortesia internacional. Destarte, desenvolve em largos traços, o tratamento normativo da cooperação jurídica internacional mercosulina, em matéria cível e criminal, com ênfase nos Acordos de Cooperação Judiciária. Por fim, conclusivamente busca sustentar que, em face do desenvolvimento da cooperação jurídica na arena MERCOSUL esta alberga um embrionário direito processual de integração, inclusive, com estatuto epistemológico próprio e fundamental para o aprofundamento do processo de integração sul-americano. Ademais, evidencia a centralidade dos direitos humanos como um paradigma hermenêutico adequado à problemática da operacionalização das distintas formas atuais de cooperação jurídica internacional.

Palavras-Chave: MERCOSUL. Cooperação Jurídica Internacional. Direito Processual de Integração. Direitos Humanos. Integração.

Revista de Direito Brasileira | São Paulo, SP | v. 16 | n. 7 | p. 428 - 444 | Jan./Abr. 2017 
ABSTRACT: The issue of international legal cooperation raises complex issues, whose gaps and uncertainties require and require responses under construction. Due to the increase in activities that transcend political boundaries, there has been a boost in legal cooperation between countries. This article proposes to examine the development of the institute of international legal cooperation within MERCOSUR with a view to highlighting its instrumental and neuralgic character to the consolidation of the integration process within this regional bloc. To this end, it presents the institute of international legal cooperation based on its delineations, its aims, and its own principiology. It highlights the nature of legal cooperation in contemporary times as a legal imperative and not as mere international courtesy. Thus, it develops in broad strokes the normative treatment of mercosuline international legal cooperation, in civil and criminal matters, with emphasis in the Agreements of Judicial Cooperation. Lastly, it conclusively seeks to maintain that, in view of the development of legal cooperation in the MERCOSUR arena, it embodies an embryonic procedural right of integration, including its own epistemological status and fundamental for deepening the South American integration process. In addition, it highlights the centrality of human rights as a hermeneutic paradigm appropriate to the problem of the operationalization of the different current forms of international legal cooperation.

Keywords: MERCOSUR. International Legal Cooperation. Procedural Law of Integration. Human rights. Integration.

SUMÁRIO: Introdução; 1. Cooperação Jurídica na contemporaneidade: comitas gentium ou imperativo de direito; 2. Cooperação Jurídica em matéria cível e criminal no âmbito do MERCOSUL; 3. Impasses e desafios à cooperação jurídica internacional: harmonizar juridicamente como estratégia à integração. Conclusão; Referências Bibliográficas.

\section{INTRODUÇÃO}

O momento atual revela o auge do fenômeno da mundialização ou globalização ${ }^{1}$, tendo em vista o incremento das relações sociais transfronteiriças ou plurilocais ao redor do globo. Nesse contexto globalizado marcado pela assimetria entre os países ${ }^{2}$ no qual existe a potencialização das interações entre os indivíduos, a cooperação internacional, em especial, a cooperação judicial ou jurídica ${ }^{3}$ revela-se paulatinamente imperiosa e superlativa.

A temática da cooperação jurídica internacional apresenta questões complexas, cujas lacunas e incertezas impõem e demandam respostas em construção. Devido ao aumento de

\footnotetext{
${ }^{1}$ A globalização apresenta-se enquanto conceito como um fenômeno complexo, composto de diversas dimensões e facetas econômicas, politicas, culturais, ambientais, religiosas, jurídicas, que podem convergir na esteira das teorizações weberianas, para o tipo ideal, ou seja, "uma crescente interconexão em vários níveis da vida cotidiana a diversos lugares longínquos no mundo." LIMA, Abili Lázaro Castro de. Globalização econômica, política e direito: análise das mazelas causadas no plano político-jurídico. Porto Alegre: Sergio Antonio Fabris Editor, 2002, p. 127; p 138. John Gray definiu globalização econômica como a "expansão mundial da produção industrial e de novas tecnologias promovida pela mobilidade irrestrita do capital e a total liberdade do comércio". GRAY, John, Falso amanhecer: os equívocos do capitalismo global. Rio de Janeiro: Record, 1993, p. 174. Alguns autores identificam uma forte ligação entre os conceitos de globalização e o neoliberalismo, analisando-os como um só, sob a denominação globalização neoliberal. Outros, ainda, vislumbram uma identidade entre os dois fenômenos.

${ }^{2}$ ROBERT, Jacques. Droits de l'homme et libertés fondamentales. 5. ed. Paris: Montchrestien, 1994.

${ }^{3}$ A expressão cooperação judicial internacional designa o intercâmbio de atos de autoridades judiciais dos Estados, entretanto, na cooperação jurídica internacional os sujeitos intervenientes nem sempre serão autoridades judiciais, v.g., juízes de direito ou de Tribunais, podendo ser autoridades de outra natureza, como os membros de Ministério Público ou autoridades administrativas, tais como, Ministério da Justiça, polícias, dentre outros. Cf. PERUCHIN, Marcelo Caetano Guazelli. A proteção dos direitos fundamentais no cenário da cooperação judicial penal internacional. In: PAGLIARINI, Alexandre Coutinho; CHOUKR, Fauzi Hassan (Coords.). Cooperação Jurídica Internacional. Belo Horizonte: Editora Fórum, 2014, pp, 225-243, p. 225.
} 
atividades que transcendem as fronteiras políticas, houve um impulso do desenvolvimento da cooperação jurídica entre países. Indubitavelmente constitui uma questão central o entendimento da tensão imanente entre a ideia de soberania (sua definição e os seus limites) ${ }^{4}$ e os interesses dos distintos sujeitos afetados nos pedidos de cooperação jurídica.

Há necessidade de se conciliar a aplicação do direito estrangeiro em face das distintas interpretações dos direitos e garantias fundamentais dos envolvidos, tendo vista alegações de salvaguarda de regras imperativas do foro ou respeito à cláusula de ordem pública.

Assim, em tempos de potencialização dos efeitos do processo de mundialização, urge compreender a cooperação judicial não como mera espécie de cortesia internacional ou comitas gentium $^{5}$, mas como algo juridicamente regulado, sendo, inclusive, em inúmeros casos, objeto de regulação tanto pela ordem jurídica interna quanto pela internacional. ${ }^{6}$

Destaca-se que o instituto da cooperação internacional, não obstante, ser objeto de análise de inúmeras pesquisas voltadas, em especial, à cooperação judicial internacional certamente desafia maiores verticalizações, sobretudo, no que tange aos seus possíveis impactos e efeitos em determinados âmbitos do Direito. ${ }^{7}$

Como é sabido, o tema ora em comento, geralmente é estudado pelo Direito Internacional Privado, especificamente pela parte deste que trata do chamado Direito Processual Civil Internacional. ${ }^{8}$

Destarte, o Direito Internacional Público, desde há muito, também se dedica à cooperação jurídica internacional por meio da busca e viabilização do imprescindível consenso para o estabelecimento das normas jurídicas e do sistema de justiça internacional. ${ }^{9}$

Tendo em vista o amplo reconhecimento do costume internacional entre os Estados consistente na obrigação de prestar auxílio mútuo, notadamente, no plano jurisdicional, a

\footnotetext{
${ }^{4}$ Jorge Miranda ensina que, no século XX, com a entrada em crise da soberania em face da "multiplicação das formas de coordenação e de subordinação vindas do Direito das Gentes, tornou-se necessário - e, porque necessário, possível - acrescentar à proteção interna da pessoa humana uma proteção internacional, ou até substituí-la por esta". MIRANDA, Jorge. Manual de Direito Constitucional, IV, 5. ed. Coimbra: Coimbra Editora, 2012, p. 42.

${ }^{5}$ Referida expressão latina foi consagrada pela Escola Holandesa, a qual sustentava o caráter puramente territorial do direito, ou seja, o estrangeiro encontrava-se obrigado a acatar e a submeter-se aos ditames da lei nacional. Todavia, o Estado por cortesia internacional poderia aplicar a sua lei pessoal. Ressalta-se, por oportuno, que não há unanimidade entre os autores quanto ao verdadeiro sentido da expressão "comitas gentium" empregada pelos juristas holandeses. A respeito de o tema conferir, PEREIRA, José Edgard Amorim. A doutrina holandesa "Comitas gentium". Disponível em: <http://www.direito.ufmg.br/revista/index.php/revista/article/viewFile/685/645> Acesso em: 31 de ago. de 2016.

${ }^{6}$ Neste sentido FERNÁNDEZ ARROYO, Diego. Derecho Internacional Privado: una mirada actual sobre sus elementos esenciales. Editora Advocatus. Córdoba: 1998, pp. 62-63.

7 A temática da cooperação jurídica internacional certamente merece atenção pelos estudiosos do Direito Internacional Contemporâneo quer seja pelo DIPriv, quer seja pelo DIP. Conhece ainda repercussões em ramos destinados às ordens internas estatais, como o Direito Processual e o Direito Constitucional, especialmente, aos direitos e garantias fundamentais, Direito Penal, Direito de Família, dentre outros. Também exerce influência sobre ramos considerados sui generis, tais como, o Direito da Integração, o Direito Comunitário posto que não pertençam ao direito internacional tampouco ao direito interno. Cf. GOMES, Eduardo Biacchi. Manual da Integração Regional. 2. Ed. rev. atual. Curitiba: Juruá, 2015, p. 88.

${ }^{8}$ Cf. ARAÚJO, Nádia. Direito Internacional Privado: teoria e prática. Rio de Janeiro: Renovar, 2007, pp. $265-271$.

${ }^{9}$ Conforme ensina Nádia de Araújo, há duas visões sobre as quais se pode examinar a cooperação judicial internacional, de um lado a visão ex parte principis que se refere a relação do Estado com os demais no plano internacional fundada no lógica da governabilidade estatal; por outro lado, a visão ex parte populi, voltada às pessoas que são atingidas pelas medidas solicitadas, tendo em consideração os seus direitos. ARAÚJO, Nádia. A importância da cooperação jurídica internacional para a atuação do Estado brasileiro no plano interno e internacional. In: BRASIL. Ministério da Justiça. Departamento de Recuperação de Ativos e Cooperação Jurídica Internacional, Secretaria Nacional de Justiça. Manual de Cooperação Jurídica Internacional e Recuperação de Ativos: matéria penal, Brasília, 2008, p. 38. No mesmo sentido, CERVINI, Raul; TAVARES, Juarez. Princípios aplicáveis à cooperação judicial penal internacional no protocolo do Mercosul. Trad. Marcelo Caetano Guazzelli Peruchin. São Paulo: Revista dos Tribunais, 2000, pp. 81-82.
}

Revista de Direito Brasileira | São Paulo, SP | v. 16 | n. 7 | p. 428 - 444 | Jan./Abr. 2017 
assistência recíproca e efetiva entre os países, em prol das coletividades das pessoas ${ }^{10}$ se apresenta como um dos desafios centrais do Direito Internacional do século XXI. Assim, a cooperação jurídica internacional carece de reflexões sob a perspectiva crítica dos direitos humanos. ${ }^{11}$

O presente artigo se propõe a examinar o desenvolvimento do instituto da cooperação jurídica internacional no âmbito do MERCOSUL, na medida em que impacta os sistemas jurisdicionais de todos os seus Estados Partes sustenta que a conformação de um sistema processual dotado de princípios e regras próprios revela-se imprescindível à verticalização do processo de integração mercosulino. Ademais, evidencia a centralidade dos direitos humanos como um paradigma hermenêutico adequado à problemática que envolve a operacionalização das distintas formas atuais de cooperação jurídica internacional.

Para tanto, procura-se ao longo do presente artigo analisar a cooperação jurídica internacional no contexto atual, a partir dos seus delineamentos, dos seus princípios e regras, dos seus instrumentos jurídicos, e das suas finalidades. Após evidenciar os traços desse sistema jurídico processual, aqui entendido como autônomo e específico, pretende-se lançar luzes sobre o caráter da cooperação jurídica na contemporaneidade não como mera cortesia internacional, mas como imperativo de direito.

Em seguida, apresenta-se em largos traços o tratamento normativo da cooperação jurídica internacional mercosulina em matéria cível e criminal, enfatizando os Acordos de Cooperação Judiciária em matéria processual vigentes no MERCOSUL. ${ }^{12}$

Por fim, procura sustentar que o bloco regional MERCOSUL conta com um embrionário direito processual de integração - dotado de um estatuto epistemológico próprio - que, apesar de precário e edificado sobre os parâmetros clássicos do Direito Internacional, ou seja, a celebração de instrumentos jurídicos internacionais.

Tal sistema jurídico revela-se importante ao aprofundamento do processo de integração, na medida em que impacta os sistemas jurisdicionais de todos seus Estados-Membros com reflexos também em outras áreas fundamentais, como a política e a economia.

\section{A COOPERAÇÃO JURÍDICA NA CONTEMPORANEIDADE: COMITAS GENTIUM OU IMPERATIVO DE DIREITO}

Pode-se afirmar que, desde a Antiguidade, a humanidade continuamente busca estabelecer vínculos que transcendem a sua comunidade de origem. Impulsionada pelos mais diversos desejos, tais como, garantia da própria sobrevivência, melhoria das condições materiais e culturais de vida, motivos sentimentais, fatores climáticos, garantia da convivência recíproca, dentre outros.

Tais laços e relações contribuem à origem de fatos com contatos com duas ou mais comunidades sociais, o implica, às vezes, debates sobre a sua adequada regulamentação jurídica,

\footnotetext{
${ }^{10} \mathrm{Na}$ seara internacional, o indivíduo, constitui-se em ente primário e é sujeito de direitos e garantias, implica que o direito internacional adquira traços cooperativos e cosmopolitas. Cf. MACHADO. Jónatas E. M. Direito internacional: do paradigma clássico ao pós-11 de setembro. 3. ed. Coimbra: Coimbra Ed., 2006, p. 363.

${ }^{11}$ JAYME, Erick. Le droit international prive du nouveau millenaire: la protection de la personne humaine face a la globalisation. In: L'Académie de Droit International de la Haye. Recueil des Cours: Collected Courses of the Hague Academy of International Law. London: Nijhoff, 2000, t. 282, Collection, pp. 9-40.

12 Especialmente os seguintes: o Protocolo de Cooperação e Assistência Jurisdicional em matéria civil, comercial, trabalhista e administrativa (Las Leñas - 1992); Protocolo de Medidas Cautelares (Ouro Preto - 1994); Acordo sobre o Benefício da justiça gratuita e a assistência jurídica gratuita entre os Estados-Partes do MERCOSUL, a República da Bolívia e a República do Chile (Florianópolis - 2000); Acordo de Cooperação e Assistência Jurisdicional em matéria civil, comercial, trabalhista e administrativa entre os Estados Partes do MERCOSUL, a República da Bolívia e a República do Chile (Buenos Aires, 2002). Em matéria penal, o Protocolo de Assistência Jurídica Mútua em Assuntos Penais, o chamado Protocolo de San Luiz (1996).
}

Revista de Direito Brasileira | São Paulo, SP | v. 16 | n. 7 | p. 428- 444 | Jan./Abr. 2017 
assim como a escolha de uma norma jurídica estrangeira para reger fatos e relações que apresentam conexão com mais de um ordenamento jurídico.

A cooperação judicial internacional, após a Segunda Guerra Mundial, intensificou-se encontrando nos instrumentos jurídicos internacionais bilaterais e multilaterais mecanismos de impulso e estímulo ao seu desenvolvimento.

No século XXI, um dos desafios do Direito Internacional consistente no reconhecimento do outro manifestado pelo respeito, tolerância e pelo reconhecimento das diferenças, situa-se no necessário auxílio entre as jurisdições no que tange ao cumprimento de pedidos, medidas e decisões.

Nesse contexto, como tema de singular relevância no diálogo das instâncias nacional e internacional surge à cooperação jurídica internacional. Esta, comumente é entendida como complexo de medidas e instrumentos cujos órgãos competentes dos Estados solicitam e prestam colaboração recíproca visando empreender, em seu território, atos pré-processuais ou processuais de interesse da jurisdição estrangeira na seara cível e/ou criminal.

Sinteticamente, esse intercâmbio internacional pode ser definido como o cumprimento extraterritorial de medidas pré-processuais ou processuais de outro Estado, ou ainda, a facilitação de ação do Estado solicitante na persecução de um ilícito.

A partir do delineamento conceitual, projetam-se as mais diferentes classificações doutrinárias, quais sejam: $i$ ) cooperação ativa e passiva; ii) cooperação processual e administrativa; $i i i$ ) cooperação por autoridades judiciais e por outras autoridades; $i v$ ) cooperação conjunta e cooperação singular.

Revela-se de suma importância, a análise minuciosa de cada mecanismo ${ }^{13}$ e dos desdobramentos das complexas questões que o envolvem. ${ }^{14}$ Por conseguinte, as distintas abordagens que pretendem apresentar uma definição à cooperação internacional ${ }^{15}$ indicam a $^{2}$ complexidade e a pluralidade das medidas que a comunidade internacional passou a adotar no combate dos ilícitos em geral, cujo caráter pode ser jurídico ou administrativo. ${ }^{16}$

Com a finalidade de facilitar o acesso à justiça, gradativamente, tem-se desenvolvido um conjunto de normas nacionais e internacionais tendentes a reger atos de colaboração entre Estados, ou mesmo entre Estados e organizações internacionais. ${ }^{17}$ Destaca-se que a ideia de aproximação entre pessoas é inerente à natureza do ato de cooperar ${ }^{18}$.

No que tange aos instrumentos que visam simplificar o intercâmbio interjudicial, mencionam-se as denominadas autoridades centrais ${ }^{19}$. Estas constituem organismos

\footnotetext{
${ }^{13}$ Importantes aportes acerca da classificação dos mecanismos da cooperação internacional, ver BECHARA. Fábio Remazzini. Cooperação jurídica internacional em matéria penal: eficácia da prova produzida no exterior. São Paulo: Saraiva, 2011, pp. 297-325.

${ }^{14} \mathrm{Tal}$ análise escapa do objetivo central proposto pelo presente artigo, desse modo, delimita-se apenas a oferecer uma visão geral das linhas gerais necessárias ao enfrentamento da matéria.

${ }^{15}$ Também aqui, como nos demais ramos da ciência jurídica em geral, há que se precaver contra os problemas do reducionismo de definições; estas, pela dinâmica da realidade e com a historicidade temporal, tendem a se revelar incompletas.

${ }^{16}$ Sob a nomenclatura de administrativo, situam-se todas as medidas que, para sua operacionalização, dispensam o reconhecimento ou execução de decisão judicial proferida no estrangeiro, ou ainda a identificação de ao menos uma ou mais autoridades judiciárias ou dotadas de poderes judiciais, conforme preconiza a legislação brasileira, v.g., as redes de cooperação e cooperação policial (Rede Iberoamericana de Cooperação Judicial - IberRED; Rede Hemisférica de Intercambio de Informações para o Auxílio Jurídico Mútuo em Matéria Penal e de Extradição; Rede de Cooperação Jurídica e Judiciária Internacional dos Países de Língua Portuguesa CLCP).

${ }^{17} \mathrm{Cf}$. ABADE, Denise. Direitos fundamentais na cooperação jurídica internacional: extradição, assistência jurídica, execução de sentença estrangeira e transferência de presos. São Paulo: Saraiva, 2013.

${ }_{18}^{18}$ Cooperar significa aproximar-se do outro, encurtar distâncias, agir com o outro para um mesmo fim, contribuir.

${ }^{19}$ As autoridades centrais tiveram a sua origem na Convenção de Haia. No caso do Brasil, foi designado como autoridade central para fins de cooperação jurídica internacional, tanto em matéria civil quanto em matéria penal o Departamento de Recuperação de Ativos e Cooperação Jurídica Internacional - DRCI por meio de Decreto $\mathrm{n}$. 4.991/2004, sendo que o Decreto n. 6.061/2007 descreve as funções da autoridade central. Vale ressaltar que o Revista de Direito Brasileira | São Paulo, SP | v. 16 | n. 7 | p. 428 - 444 | Jan./Abr. 2017
} 
internacionais estabelecidos em Acordos ou Tratados que inclusive, a depender do teor da respectiva normativa internacional podem prestar auxílio direto dispensando o exequatur pelo Judiciário do Estado solicitado.

Em face de uma realidade transfronteiriça e levando-se em conta o atual estágio do processo de mundialização ${ }^{20}$, a cooperação jurídica internacional deve ser entendida não somente como uma espécie de cortesia internacional entre os Estados, mas sim como uma forma de obrigação ou imperativo do Direito que assegure juridicamente as relações sociais desenvolvidas dentro dessa nova realidade.

A partir dessa perspectiva, há um dever genérico de prestação de cooperação internacional na medida em que os instrumentos jurídicos internacionais firmados entre os Estados constituem direitos e obrigações entre as partes, tendo por prioridade a solidariedade. Portanto, o cumprimento de atos de cooperação representam um dever do país solicitado, não mais um mero favor, sob pena de fragilizar o próprio sistema judicial.

De tal modo que, da natureza em si da cooperação jurídica internacional, infere-se a sua relevância, qual seja, cooperar implica auxiliar, contribuir com o outro mediante a criação de mecanismos ou estruturas capazes de unir, tendo em vista a busca de pontos de convergência e da necessidade de garantir o postulado nodal do Estado Liberal, ou seja, a segurança jurídica.

Tais desafios impostos pela mundialização podem ser visualizados de forma superlativa por meio das "lentes de aumento" dos processos de integração. Os blocos regionais constituem "sistemas menores" dentro de um sistema maior e mais complexo - composto de diferentes atores e sujeitos de direito internacional que no presente contexto encontram-se jungidos pelo diálogo permanente, avalizado pelo Direito e pelos respectivos sistemas judiciários, com vistas a garantir a sua própria viabilidade.

A rigor, ao se mencionar a obrigação de cooperar, a doutrina frequentemente afirma a necessidade de se levar em conta as situações e os limites impostos à cooperação, tais como, a proteção da higidez dos direitos e garantias fundamentais ${ }^{21}$ e a preservação das cláusulas de proteção à ordem pública e da especialidade. ${ }^{22}$

O reconhecimento dessas balizas não deve conduzir à ineficácia da cooperação internacional, mas a consagração dos ditames do Estado de Direito, como a observância do devido processo legal e os seus princípios consectários.

Assim, não se deve relegar ao segundo plano os direitos e as garantias fundamentais ${ }^{23}$ do sujeito concernido no pedido de cooperação, em nome do critério da celeridade ${ }^{24}$. Atualmente, tais direitos fundamentais, além de constituírem direitos subjetivos, ostentam também o status de garantia constitucional. ${ }^{25}$

instrumento jurídico internacional pode indicar outro órgão para exercer tal função, que esteja vinculado mais estritamente com o objeto do respectivo Acordo ou Tratado Internacional no qual haja previsão. Cf. ARAÚJO, Nádia, op. cit.,p. 40.

${ }^{20}$ No final do século passado, a mundialização marcou o ocaso da bipolaridade da Guerra Fria.

${ }^{21}$ Ibidem.

${ }^{22}$ Cf. afirmam GIACOMOLLI e DALLA ROSA DIETRICH está no binômio necessidade de cooperação internacional e limites à satisfação dessa necessidade a sugestão para o desenvolvimento da cooperação pena internacional. GIACOMOLLI, Nereu José; DIETRICH, Eduardo Dalla Rosa. Necessidade e limites na cooperação jurídica internacional em matéria criminal - ordem pública e especialidade. In: PAGLIARINI, Alexandre Coutinho; CHOUKR, Fauzi Hassan (Coords.). Cooperação Jurídica Internacional, op. cit., pp. 258.

${ }^{23}$ Para Luigi Ferrajoli, direitos fundamentais são os direitos subjetivos que correspondem universalmente a todos os seres humanos enquanto dotados de status de pessoas. FERRAJOLI, Luigi. Derechos y garantias: la ley del más débil. Madrid: Trotta, 1999, p. 37. Destarte em FERRAJOLI, Luigi. Los fundamentos de los derechos fundamentales. Madrid: Trotta, 2009, pp. 19-22.

${ }^{24}$ TROTA. O lugar do crime no Mercosul: as fronteiras da cooperação jurídica internacional contemporânea, p. 128; pp. 126-131.

${ }^{25}$ SARLET, Ingo Wolfgang. A eficácia dos direitos fundamentais, p. 75; pp. 86-87; p. 268. PEREZ LUNO, Antonio-Enrique. Los derechos fundamentales. Madrid: Technos, 8. ed., 2004, p. 25.

Revista de Direito Brasileira | São Paulo, SP | v. 16 | n. 7 | p. 428- 444 | Jan./Abr. 2017 
Nessa toada, para que seja possível um aprofundamento no processo de integração, em especial, à consolidação de um mercado comum que demanda a livre circulação dos quatro fatores de produção, ou seja, bens, pessoas, serviços e capitais, fazem-se necessária à presença de instrumentos aptos a conferir segurança jurídica às múltiplas interações estabelecidas em bases comunitárias regionais e a salvaguardar os direitos fundamentais ou humanos. ${ }^{26}$

O MERCOSUL enquanto organização internacional de caráter regional ${ }^{27}$ origina-se, inexoravelmente, em decorrência e no clímax do fenômeno da mundialização ${ }^{28}$.

De tal maneira que, pode-se afirmar que o seu progresso está condicionado e emoldurado, dentre outros fatores, pelo fracasso e/ou logro em garantir juridicamente as relações intra-bloco, o que transcende a mera perspectiva institucional da organização em tela.

Destaca-se que, no atual estágio de integração do bloco regional do Cone-Sul, o mesmo já dispõe de instrumentos jurídicos vinculantes qualitativamente relevantes. Mencionados instrumentos considerados em conjunto podem ser considerado como o exórdio de um direito processual da integração, consistente em um conjunto de normas jurídicas tendentes a regular a cooperação processual em bases regionais mercosulinas.

Embora esse sistema processual possa ser considerado incipiente, não obstante, a necessidade de avanços substanciais com vistas a atingir níveis satisfatórios, tal sistema processual mercosulino - cujas regras atinentes à cooperação jurídica internacional ocupam um locus de destaque - guarda especial importância à integração, tanto em termos jurídicos quanto em termos socioeconômicos.

É imprescindível o delineamento de uma teoria geral da cooperação jurídica internacional $^{29}$ em âmbito regional, com capacidade de elencar as diretrizes principiológicas, de organizar os elementos comuns de cada modalidade cooperativa, assim como evidenciar os seus reais efeitos e limitações.

Além disso, contribui à uniformização interpretativa das normas jurídicas previstas nos distintos instrumentos jurídicos que compõem o sistema de integração mercosulino, bem como a aplicação de determinada regra cooperacional respeite o pilar da integração atinente à confiança recíproca.

\section{COOPERAÇÃO JURÍDICA EM MATÉRIA CÍVEL E CRIMINAL NO ÂMBITO DO MERCOSUL}

Ao longo dos seus vinte e cinco anos de existência, o MERCOSUL vem delineando um sistema de cooperação jurídica em diversas áreas, cível, penal, administrativa, assim como, em importantes âmbitos extrajurídicos como são os casos da política e da economia.

Tal evolução, ainda que, pode ser considerada lenta, gradativa e assistemática, inclusive, em função das próprias idiossincrasias do bloco, evidencia a existência de instrumentos jurídicos relevantes no que tange a regulamentação de tais questões.

\footnotetext{
${ }^{26} \mathrm{O}$ que se deseja destacar aqui é a sua nota de fundamentalidade, independentemente das diferenças técnicoconceituais entre os direitos humanos e os direitos fundamentais, sendo os primeiros àqueles inscritos nos instrumentos jurídicos internacionais e os últimos àqueles com previsão nos textos constitucionais dos Estados. Cf. PEREZ LUÑO, Los derechos fundamentales, op. cit., p. 44-46.

${ }^{27}$ O Protocolo de Ouro Preto (1994) conferiu ao MERCOSUL personalidade jurídica internacional, e marcou a etapa de transição entre a zona de livre comércio e a união aduaneira, não obstante, até o momento, uma união aduaneira imperfeita.

${ }^{28}$ O sociólogo espanhol Manuel Castells afirma que “O século XXI (...) Estados-nação sobreviverão, mas não sua soberania. Eles se unirão em redes multilaterais com geometria variável de compromissos, responsabilidades, alianças e subordinações”. CASTELLS, Manuel. Fim de milênio, op. cit., p. 430.

${ }^{29}$ Cf. RAMOS, André de Carvalho. A pluralidade das ordens jurídicas e a nova centralidade do Direito Internacional. Boletim da Sociedade Brasileira de Direito Internacional, v. 1, p. 19-45, 2013.

Revista de Direito Brasileira | São Paulo, SP | v. 16 | n. 7 | p. 428 - 444 | Jan./Abr. 2017
} 
O sistema processual mercosulino em matéria de cooperação jurídica internacional é formado por um conjunto de instrumentos jurídicos internacionais - Acordos bilaterais, Tratados regionais e multilaterais, muitos dos quais, já devidamente internalizados pelas ordens jurídicas dos Estados-Partes.

Referidos instrumentos versam acerca da distribuição da competência internacional em matéria contratual, modificando as disposições da ordem interna no que tange à jurisdição internacional. Além disso, contempla vários acordos cujo teor elenca disposições convencionais relevantes acerca do reconhecimento de sentenças e laudos arbitrais estrangeiros proferidos por autoridades competentes no âmbito do MERCOSUL.

Ademais, fazem-se presentes ainda, inúmeros acordos que visam garantir distribuição equitativa no que tange à facilitação e acesso à jurisdição pelos cidadãos residentes no interior do bloco. Acrescenta-se que, para alguns países a cooperação jurídica se dá com base na promessa de reciprocidade.

Em suma, os instrumentos jurídicos internacionais multilaterais e bilaterais que emolduram o direito processual da integração mercosulino, são os seguintes: i) Protocolo de Las Leñas $^{30}$; ii) Protocolo de Buenos Aires sobre jurisdição em matéria contratual ${ }^{31}$; iii) Protocolo de Medidas Cautelares ${ }^{32}$; iv) Protocolo de São Luís ${ }^{33}$; v) Acordo sobre arbitragem comercial internacional $^{34}$; vi) Acordo sobre o benefício da justiça gratuita e a assistência jurídica gratuita entre os membros do MERCOSUL. ${ }^{35}$

No que tange ao MERCOSUL, dentre os instrumentos jurídicos mencionados, cabe destacar o Protocolo de Las Leñas (1992), internalizado ao direito brasileiro por meio do Decreto n. 2.067, de 12/11/1996 e o Acordo de Cooperação e Assistência Jurisdicional entre os Estados Partes do MERCOSUL, a República da Bolívia e a República do Chile (2002).

Referidos Acordos estabelecem as diretrizes da cooperação e assistência judicial em matéria civil, comercial, trabalhista e administrativa entre os países do Cone Sul. Resumidamente, são responsáveis por regula à produção de provas, as trocas de informações, o reconhecimento de sentenças e a cooperação em geral interjurisdicional dos Estados Partes do MERCOSUL.

Além dos Acordos em matérias processuais cíveis retro mencionados, cabe aduzir o Acordo MERCOSUL sobre Livre Residência e o Acordo Previdenciário do MERCOSUL e Declaração Sociolaboral. O que se busca promover, em verdade, por meio do estabelecimento desses acordos é uma harmonização legislativa em assuntos estratégicos para o bloco.

\footnotetext{
${ }^{30}$ O Acordo de cooperação em matéria civil, comercial, trabalhista e administrativa, denominado Protocolo de Las Leñas foi promulgado por meio do Decreto n. 2.067, de 12/11/1996.

${ }^{31}$ Mencionado Protocolo foi promulgado pelo Decreto n. 2.095, de 17/12/1996.

${ }^{32}$ Mencionado Protocolo de medidas cautelares foi promulgado pelo Decreto n. 2.626, de 15/06/1998.

${ }^{33}$ Mencionado Protocolo de São Luís sobre matéria de responsabilidade civil de acidentes de transito, obteve promulgação por meio do Decreto n. 3.856, de 03/07/2001.

${ }_{34}^{34}$ Mencionado Acordo foi promulgado pelo Decreto n. 4.719/04/06/2003.

${ }^{35}$ Promulgado pelo Decreto n. 6.679, de 08/12/2008. Registra-se por oportuno, que no Brasil, o Ministério da Justiça é quem exerce o papel de autoridade central para cooperação jurídica internacional, que o faz por meio do Departamento de Recuperação de Ativos e Cooperação Jurídica Internacional (DRCI) e do Departamento de Estrangeiros (DEEST), conforme dispõe o Decreto n. 6.061/2007. Ao Departamento de Estrangeiros compete analisar e tramitar as solicitações de transferência de pessoas condenadas e os pedidos de extradição. Ao Departamento de Recuperação de Ativos e Cooperação Jurídica Internacional compete analisar e tramitar as demais modalidades de pedidos de cooperação jurídica internacional. Para a Convenção sobre Prestação de Alimentos no Estrangeiro (1956), a Procuradoria Geral da República exerce a função de autoridade central; para a Convenção de Haia sobre os aspectos civis do sequestro internacional de crianças (1980); a Convenção de Haia relativa à proteção das crianças e à cooperação em matéria de adoção internacional (1993); e a Convenção Interamericana sobre restituição internacional de menores (1989), a Secretaria de Direitos Humanos da Presidência da República desempenha tal função.
}

Revista de Direito Brasileira | São Paulo, SP | v. 16 | n. 7 | p. 428- 444 | Jan./Abr. 2017 
A cooperação jurídica em matéria penal é um complexo instituto que tem sido utilizado ao longo do tempo pelos Estados para se evitar, sobretudo, a impunidade. A ilicitude penal estendeu suas raízes extrafronteiras e a efetividade da persecutio criminis restaria comprometida caso remanescesse isolada e com fronteiras fechadas. ${ }^{36}$

Distintos e diversos são os tipos de atos que podem ser realizados pela via da cooperação. Exemplificativamente, citam-se, a extradição ${ }^{37}$, a carta rogatória em matéria penal ${ }^{38}$, a transferência de presos condenados e a homologação de sentença penal estrangeira ${ }^{39}$, a assistência mútua ${ }^{40}$, o bloqueio de ativos e produtos de crime, dentre outros.

No âmbito da cooperação interjurisdicional na área penal cabe mencionar o acordo sobre o mandado MERCOSUL de captura (MMC) aprovado em 16 de dezembro de 2010 por meio da Decisão do CMC n. 48/2010 ${ }^{41}$ com vistas a buscar soluções jurídicas tendentes ao reforço do processo de integração mediante a utilização de formas mais ágeis ao combate aos crimes transnacionais.

Pode-se afirmar que o MERCOSUL conta com um corpus iuris próprio que tem como eixo fundamental o Tratado de Assunção. Também conta com um conjunto de instrumentos jurídicos responsáveis por conformar o denominado direito originário, bem como se compõem de um conjunto de normas jurídicas consideradas derivadas.

Acrescentem-se à compreensão do referido sistema processual ${ }^{42}$ assim como os seus limites $^{43}$, o conjunto de princípios conformadores do direito processual internacional, em

${ }^{36}$ Cf. ZAPATERO, Luis Arroyo. A harmonização internacional do Direito Penal: ideias e processos. Revista Brasileira de Ciências Criminais. São Paulo, n. 84, pp. 49-76, 2010, p. 55.

${ }^{37}$ Os tratados multilaterais de extradição celebrados pelos Brasil no âmbito do MERCOSUL são os seguintes: MERCOSUL, promulgado pelo decreto n. 4.975/04 e MERCOSUL, Bolívia e Chile promulgado pelo Decreto $\mathrm{n}$. $5.867 / 06$.

${ }^{38}$ A despeito do tramite das cartas rogatórias pela via diplomática dispensarem a celebração de tratados, o Brasil firmou alguns tratados bilaterais atinentes ao cumprimento de cartas rogatórias em matéria penal, com a Bolívia, Argentina e Uruguai, além da Convenção Interamericana sobre Cartas Rogatórias (1975). Destaca-se que, o art. 105, inciso I, alínea "i" estabelece a competência do Superior Tribunal de Justiça para a concessão de exequatur às cartas rogatórias (alteração de competência dada pela EC 45/2004 que deslocou tal competência do STF para o STJ). Todavia, permanece inalterado o artigo 109, da CF/88, que dispõe sobre a competência da Justiça Federal para sua execução. Mencionam-se ainda as disposições infraconstitucionais sobre a referida matéria, os artigos 783 a 786 do Código de Processo Penal, a Resolução n. 09, de 04/05/2009, do STJ, os artigo 65, § 1 do CPPM, especificamente aplicado para os casos de competência de a Justiça Militar, e por fim, o artigo $36, \S 1^{\circ}$ e $\S 2^{\circ}$ do CPC, aplicado subsidiariamente ao processo penal, por força da redação do artigo $3^{\circ}$ do CPP.

39 Acordo sobre Transferência de pessoas condenadas entre os Estados Partes do MERCOSUL firmado em 16/12/2004 e promulgado pelo Decreto n. 291/2007; Acordo sobre Transferência de pessoas condenadas entre os Estados-Parte do MERCOSUL, com a República da Bolívia e a República do Chile firmado em 16/12/2004 e promulgado pelo Decreto n. 148/2011.

${ }^{40} \mathrm{Em}$ matéria penal, a assistência mútua tramita diretamente entre as autoridades centrais. No âmbito do espaço regional, menciona-se o Protocolo de San Luiz sobre Assistência Jurídica mútua em assuntos penais, promulgado pelo Decreto n. 3.468/2000. Pode ser objeto de pedido de assistência, a notificação, a entrega de documentos, busca e apreensão de bens e assistência ao perdimento de bens, cooperação na forma de localização ou identificação de bens ou pessoas, translado de pessoas detidas, dentre outras medidas.

${ }^{41}$ O Brasil até o momento não ratificou o texto do acordo sobre mandado MERCOSUL de captura e procedimentos de entrega entre os Estados Partes do MERCOSUL e Estados Associados, encontrando-se no momento submetido à apreciação do Congresso Nacional.

${ }^{42} \mathrm{O}$ referido sistema deve respeitar, segundo afirma Delmas-Marty, certas imposições de coerência lógica (critério interno de validade) e de adequação à realidade (critério externo de validade). DELMAS-MARTY, Mireille. Modelos e movimentos de política criminal. Tradução de Edmundo Oliveira. Rio de Janeiro: Revan, 1992, p. 51.

${ }^{43}$ No tocante à matéria da limitação, ver as contribuições de ARAS, Vladmir. O sistema de cooperação penal Brasil/Estados Unidos. In: BALTAZAR JR., José Paulo; LIMA, Luciano Flores de (Org.). Cooperação Jurídica internacional em matéria penal. Porto Alegre: Verbo Jurídico, 2010, pp. 321-400, p. 374 e ss.

Revista de Direito Brasileira | São Paulo, SP | v. 16 | n. 7 | p. 428 - 444 | Jan./Abr. 2017 
especial, os princípios específicos ao direito processual de integração mercosulino, notadamente, àqueles voltados à cooperação jurídica internacional. ${ }^{44}$

No que pertine aos princípios aplicáveis à cooperação jurídica penal internacional, a partir da análise do Protocolo de San Luiz que regula a matéria no MERCOSUL à doutrina tem agrupado os princípios em três grandes grupos, a saber: os princípios funcionais, os princípios de garantia e os princípios intradogmáticos de limitação material e formal ${ }^{45}$. Acrescenta-se a este rol principiológico o princípio do contraditório. ${ }^{46}$

Assim, evidencia-se na seara do MERCOSUL um sistema jurídico composto por um complexo de normas jurídicas interligadas entre si, estruturadas, hierarquizadas e/ou subordinadas, e que guarda certa proximidade com a noção de sistema jurídico internos dos Estados $^{47}$.

Ademais, o incipiente sistema jurídico processual de integração mercosulino somente pode ser suficientemente interpretado e aplicado, caso seja contextualizado de modo adequado. Ou seja, de maneira a dialogar com todas as demais normas jurídicas que compõem o sistema jurídico mercosulino, além de estar obrigado a levar em consideração o direito interno dos Estados Partes.

Frisa-se que, todo sistema jurídico para que tenha a sua eficácia garantida demanda um sistema de solução de controvérsias capaz de assegurar não só a sua aplicação, mas também garantir a uniformização de sua interpretação.

A partir desta perspectiva, a presença de um órgão competente para uniformizar a interpretação revela-se imprescindível, a fim de evitar dissonâncias no tocante ao sentido e o alcance das normas jurídicas. Ao que parece, por razões óbvias, referida uniformização de interpretação não deve ficar exclusivamente a cargo dos Tribunais nacionais dos Estados Partes.

Como é sabido, o MERCOSUL enquanto bloco econômico de natureza intergovernamental, regido pelas normas de direito internacional público não se encontra desprovido de um sistema de solução de controvérsias ${ }^{48}$.

Tal sistema de solução de controvérsias foi regulamentado pelo Protocolo de Olivos (2002) em substituição ao Protocolo de Brasília (1991). ${ }^{49}$ A despeito de evidenciar a vontade

44 Fauzi Hassan Choukr ensina que, na "conformação supranancional do processo (...) a interpretação judicial apresenta-se como protagonista”. CHOUKR, Fauzi Hassan. A reforma do CPP e a cooperação jurídica internacional. In: PAGLIARINI, Alexandre Coutinho; CHOUKR, Fauzi Hassan (Coords.). Cooperação Jurídica Internacional. Belo Horizonte: Editora Fórum, 2014, p.61.

45 A saber, os princípios funcionais, são os seguintes: princípio da primazia das normas processuais de fonte supranacional ou internacional sobre a de fonte interna; princípio da aplicação de ofício do direito comunitário; princípio de eficiência na assistência; principio do reconhecimento da diversidade dos sistemas jurídicos nos Estados Parte. Por sua vez, os princípios de garantia, são os seguintes: princípio da delimitação quanto ao âmbito e/ou alcance; princípio do respeito à ordem pública internacional do Estado requerido; princípio do respeito à lei interna processual e substancial do Estado requerido; principio da gradualidade nos requisitos; principio da reserva política; princípio do respeito à jurisdição territorial, princípio da proteção aos sujeitos do processo; princípio da especialidade com relação ao uso de informações ou provas obtidas; princípio da responsabilidade. Os princípios intradogmáticos se subdividem em dois grupos, ou seja, princípios de limitação material e princípios de limitação formal. Os primeiros referem-se aos princípios de fundamentação do Estado Democrático, a saber: proteção da dignidade humana; necessidade de pena; intervenção mínima; proporcionalidade; observância do bem jurídico; preceitos delimitativos oriundos dos direitos humanos. Já os princípios de limitação formal abarcam o princípio da legalidade e os seus consectários. Cf. CERVINI, Raul; TAVARES, Juarez. Princípios aplicáveis à cooperação judicial penal internacional no protocolo do MERCOSUL, op. cit., p. 102 e ss; p. 177 e ss.

${ }^{46}$ PERUCHIN, Marcelo Caetano Guazzelli, op. cit, p. 235.

${ }^{47}$ Sistema entendido aqui, como um conjunto de elementos distintos, que se relacionam entre si por meio de regras, princípios e postulados que compõem sua estrutura.

${ }_{48}$ A arbitragem é o sistema utilizado para a solução de controvérsias entre os Estados-Partes.

49 Cumpre salientar, que do mesmo modo que o Protocolo de Brasília, a provisoriedade também acompanha o Protocolo de Olivos. Vale lembrar que a primeira arbitragem feita pelo sistema de solução de controvérsias do MERCOSUL verificou-se em 1999, quase uma década após a aprovação do Protocolo de Brasília. O Protocolo de Olivos foi responsável por aperfeiçoar o sistema de solução de controvérsias, posto que, manteve as etapas previstas Revista de Direito Brasileira | São Paulo, SP | v. 16 | n. 7 | p. 428- 444 | Jan./Abr. 2017 
política de os Estados Partes reformularem o antigo sistema adotado, destarte, não se trata do sistema definitivo o qual requer aperfeiçoamentos com vistas a aprofundar o processo de integração.

No que pertine à resolução de controvérsia, sobretudo, devido ao caráter intergovernamental do MERCOSUL verifica-se uma predileção pelas vias e negociações diplomáticas em detrimento dos meios jurisdicionais de solução de conflito. Isso se revela, inclusive, na própria organização do sistema de solução de controvérsias que favorece o consenso político mediante a participação do Grupo Mercado Comum (GMC). ${ }^{50}$

Por conseguinte, enfatizar a decisão consensual acompanhada da ausência de um órgão supranacional, implica a transformar os agentes governamentais e seus interesses nos principais atores do processo de integração.

Consequentemente, a consolidação de um sistema de solução de controvérsias suficiente e adequado constitui um dos desafios, que impede ou inviabiliza, de algum modo, o avanço do processo integrativo sul-americano. Mencionados impasses serão pontuados no item a seguir.

\section{IMPASSES À COOPERAÇÃO JURÍDICA INTERNACIONAL: HARMONIZAR JURIDICAMENTE COMO ESTRATÉGIA À INTEGRAÇÃO.}

Pode-se afirmar que, durante todos os seus vinte e cinco de existência, houve inúmeros impasses de distintas ordens - econômica, política, jurídica, social, dentre outras - que de algum modo tiveram que ser enfrentados. Todavia, por certo, existem e existirão inúmeros outros impasses a ser superados pelo MERCOSUL.

Nesse contexto, um dos impasses audaciosos a ser enfrentados pelo bloco regional do Cone-Sul é a criação de um Tribunal de Justiça, nos moldes de Tribunais já existentes em outros processos de integração, tais como o Tribunal de Justiça da União Europeia (TJUE).

No sistema de solução de controvérsias atual, o MERCOSUL conta com um Tribunal Arbitral, com os mecanismos de reclamação e com um Tribunal Permanente de Revisão (TPR), inaugurado em 13 de agosto de 2004 e com sede na Cidade de Assunção, Paraguai. Este tribunal poderá constituir um importante avanço rumo ao que efetivamente se almeja, isto é, a criação de um Tribunal de Justiça do MERCOSUL.

Nessa toada, menciona-se a competência do mencionado Tribunal de emitir as Opiniões Consultivas (OC's). Ressalta-se o caráter não vinculante das referidas opiniões formuladas pelos Tribunais internos dos Estados Partes ao TPR, posto que juridicamente constituam pareceres.

Ao surgir à dúvida, a jurisdição nacional não se encontra obrigada a remetê-la à jurisdição do TPR. Acrescenta-se ainda a carência de vinculação jurídica o precário e dificultoso acesso ao Tribunal Permanente de Revisão (TPR). ${ }^{51}$

Conforme preconiza o artigo $3^{\circ}$ do Protocolo de Olivos (2002) e seu regulamento ${ }^{52}$, têm legitimidade ativa para solicitar as opiniões consultivas todos os Estados Membros, os órgãos do MERCOSUL e os Tribunais Superiores dos Estados Partes do bloco com jurisdição nacional. ${ }^{53}$

\footnotetext{
pelo Protocolo anterior, contudo, estabeleceu o duplo grau de jurisdição ao acrescentar o Tribunal Permanente de Revisão - TPR. Também inovou ao permitir que as altas Cortes Judiciais dos Estados Partes formulem opiniões consultivas (OC's). Cf. ACCIOLY, Elizabeth. Um olhar crítico sobre o protocolo de Olivos para solução de controvérsias do MERCOSUL. Temas de Integração. Coimbra: Almedina, n. 19, v. 1, 2005, pp. 47-57.

${ }^{50} \mathrm{Cf}$. VIERIA, Luciane Klein. Interpretación y aplicación uniforme del Derecho de la Integración: Unión Europea, Comunidad Andina y Mercosur. Buenos Aires, Montevideo: Editoria B de f, 2011, p. 107.

51 As matérias atinentes à tramitação e encaminhamento das opiniões consultivas estão reguladas na Decisão MERCOSUL CMC 02/2007.

${ }^{52}$ A decisão CMC 02/2007 que instituiu o regulamento de procedimentos do Protocolo de Olivos, elenca, no caso do Brasil, o Supremo Tribunal Federal (STF). Na Argentina, a Corte Suprema de Justicia de la Nación, no Paraguai e no Uruguai, a Corte Suprema de Justicia.
}

Revista de Direito Brasileira | São Paulo, SP | v. 16 | n. 7 | p. 428 - 444 | Jan./Abr. 2017 
Assim, sustenta-se aqui a necessidade de aprofundamento institucional por meio da criação ou transformação do TPR em Tribunal de Justiça do MERCOSUL com vistas a permitir o acesso à justiça ${ }^{54}$ e o resguardo da segurança jurídica eficaz e por consequência do processo integrativo.

Cabe destacar que as decisões adotadas levam em conta precipuamente os interesses dos Estados ao invés dos interesses do bloco. É preciso levar em consideração as relações de poder existentes intrabloco.

Isso em grande medida condiciona os seus avanços ou recuos. Não se pode ver o MERCOSUL como um bloco coeso, os países que o compõem possuem diferenças em termos políticos, culturais e econômicos.

Tal questão é reforçada face à ausência de órgãos supranacionais capazes de tomar decisões desvinculadas dos estritos interesses dos Estados-membros. ${ }^{55}$

O principal desafio econômico para a região parece ser promover a transformação produtiva, mas com equidade. O caminho a ser trilhado para um desenvolvimento regional eficaz pode estar no fomento à inversão do crescimento no setor externo por meio da canalização dessa inversão e crescimento aos produtos internos de maior valor agregado, evitando repetir a experiência de várias economias latino-americanas ao longo dos séculos, de aplicá-la prioritariamente em bens primários.

Evidenciam-se, como problemas emergentes do modelo exportador primário, os efeitos negativos sobre a ecologia, o enfraquecimento da ação coletiva e do movimento sindical, a redução da capacidade de negociação, decorrente da reestruturação produtiva reforçada pela globalização.

Embora algumas economias do bloco tenham dados alguns sinais de recuperação, são alarmantes a sua incapacidade de alcançar verdadeiros estados de bem-estar.

Ao lado da estabilização econômica, reeditam-se os velhos e graves dilemas, pobreza, distribuição regressiva de renda, elevação do dualismo entre setores minoritários que se agregam à globalização e sua possiblidades e setores que vão sendo marginalizados do desenvolvimento. ${ }^{56}$

Assim, em conjunto com ajuste econômico faz-se necessário delinear-se um ajuste politico e social. Os consensos sociais e políticos sobre o que é possível, desejável e imprescindível aos países componentes e ao próprio bloco MERCOSUL.

\footnotetext{
53 Distintamente do modelo comunitário europeu, segundo o qual, o particular pode exigir que o magistrado encaminhe a dúvida ao TJUE, no sistema do Protocolo de Olivos o procedimento é uma faculdade apenas dos Tribunais Superiores. A partir desta configuração, questionamentos importantes surgem, tais como: a) quem pode solicitar ao STF a formulação da dúvida ao TRP? É permitida a formulação de OC's única e exclusivamente por iniciativa do STF? Segundo Dreyzin de Klor, os magistrados de primeira instância podem formular uma dúvida ao TRP, sendo que tal pedido pode ser feito de ofício pelo magistrado ou Tribunal ou ainda via petição de uma parte. DREYZIN DE KLOR, A. La primera opinión consultiva en Mercosur:¿gérmen de cuestión predicial? In: Rede. Madri, 2007.

${ }^{54}$ O PARLASUL também constitui uma tentativa de legitimar socialmente o MERCOSUL, por meio da participação e integração cidadã efetiva. A matéria acerca da representação brasileira no Parlamento do MERCOSUL encontra-se regulada atualmente pelo projeto de resolução (PRN 02/15) que substituiu a Resolução 1/11 - CN, o qual estabelecia a necessidade de eleições diretas para o Parlasul até 2014, como determinou o Conselho do Mercado Comum. Como isso não ocorreu, houve a atualização das regras, prevendo as indicações e a duração dos mandatos para a atual legislatura. O Brasil indica 37(10 senadores e 27 deputados) dos 122 integrantes do Parlasul. Diante do atraso pelos Estados Partes do bloco, com exceção apenas do Paraguai, que elegeu seus 18 membros, o CMC concedeu prazo até 2020 para que todos os países realizem eleições diretas para o Parlasul.

${ }^{55}$ FREITAS JR., Antônio de Jesus da Rocha. Manual do MERCOSUL: Globalização e Integração Regional. São Paulo: BH Editora, 2006, p. 310.

${ }^{56}$ Cf. ESPIELL, Héctor Gross. Naturaleza jurídica del Tratado de Asunción y de sus protocolos. In: CHIARELLI, Carlos Alberto Gomes (Coord.). Temas de Integração com enfoques no MERCOSUL. São Paulo: LTr, 1999, pp. 109- 121.
} 
Não se mostra verdadeira a premissa que as forças do mercado sejam a única alternativa ao desenvolvimento, também as forças políticas dos Estados e as demandas da sociedade civil são componentes que devem ser considerados nos acordos que realizam os agentes econômicos.

A integração econômica, objeto do MERCOSUL, além de constituir uma livre circulação de bens e serviços, isenta de barreiras tarifárias e não tarifárias, deve também perseguir o bem-estar social, objetivo inclusive previsto no Tratado de Assunção, por meio de uma eficaz harmonização das politicas macroeconômicas, com equalização tributária, estabilização de preços, com certa homogeneidade entre as econômicas dos países-membros.

O caminho a trilhar pelo bloco regional do Cone Sul acha-se traçado, até que se efetivem a União Aduaneira perfeita e o Mercado Comum. Consumadas, então, essas fases deverá acontecer uma coordenação politica institucionalizada com fins de se atingir uma união econômica ampliada, com moeda única e banco central, a coordenação da segurança comum e a implementação dos direitos individuais e coletivos. ${ }^{57}$

Nesse ínterim, alguns passos rumo à concretização da agenda integrativa já foram dados, em termos gerais, citam-se, o processo de convergência das ultimas exceções à Tarifa Externa Comum do MERCOSUL, a conclusão das negociações hemisféricas para a conformação da ALCA, assim como a assinatura de um Acordo-quadro entre o MERCOSUL e a União Europeia com vistas a promover uma área de livre comércio no espaço transatlântico.

Destaca-se ainda o Acordo de Livre Comércio com Israel (2007), o marco de Cooperação Econômica com o Conselho de Cooperação do Golfo (2005), e o Acordo Preferencial de Comércio firmado com a União Aduaneira da África do Sul (2008).

Desde a sua criação, o MERCOSUL, já apresenta certa consolidação de normas, o que implica sustentar a existência de um verdadeiro sistema jurídico no bloco, inclusive, com certa primazia $^{58}$ em face do Direito Internacional e dos ordenamentos jurídicos nacionais, tendo em vista sua especialidade.

O sistema jurídico de integração é formado por normas jurídicas que são acordadas, negociadas e celebradas pelos representantes dos respectivos Poderes Executivos dos Estados Partes. Sendo bloco econômico de natureza intergovernamental, as normas emanadas das instituições do MERCOSUL necessitam ser internalizadas. ${ }^{59}$

Nessa toada, os Acordos de Cooperação Judiciária do MERCOSUL, como visto, consistem em tratados ratificados entre os Estados Partes e que têm por finalidade agilizar os procedimentos atinentes ao intercâmbio interjurisdicional dos países do bloco. ${ }^{60}$

Nesse ínterim, cabe destacar que a cooperação jurídica internacional deve levar em conta a tensão imanente entre os interesses nacionais, os interesses das pessoas concretamente afetadas e os da ação judicial que transcendem os limites territoriais.

Tal embate entre a soberania e a efetividade processual imanente à aplicação das regras referentes à cooperação jurídica internacional pode se equilibrar mediante a estruturação de um cabedal teórico $^{61}$ suficiente e adequado centrado na dignidade humana.

\footnotetext{
${ }^{57}$ Idem, pp. 75-83.

${ }^{58}$ Tais normas ainda obedecem ao regramento e princípios do direito internacional e dependem das ordens jurídicas internas dos Estados Partes.

${ }^{59}$ No caso da ordem jurídica interna brasileira, somente terão vigência após autorização do Congresso Nacional da ratificação, que é competência exclusiva do Chefe do Poder Executivo, seguida a promulgação e a publicação do Decreto Presidencial, ratificador do tratado.

${ }^{60} \mathrm{O}$ cumprimento dos respectivos pedidos, há que observar o critério da lex fori, isto é, os critérios elencados na lei processual da jurisdição cujo ato deverá ser executado.

${ }^{61}$ Não há uma teoria geral que albergue os principais elementos da cooperação jurídica internacional, posto que nesta questão cada Estado tem autonomia para dela dispor livremente. Destarte, não há vetores e diretrizes interpretativas do mecanismo em comento.
}

Revista de Direito Brasileira | São Paulo, SP | v. 16 | n. 7 | p. 428 - 444 | Jan./Abr. 2017 
A interpretação a ser dada às normas jurídicas aplicáveis a cooperação jurídica deve visar o imprescindível deslinde transnacional do processo, balizada ainda pela conservação da soberania e dos princípios correlatos ${ }^{62}$, assim como pelo respeito aos direitos humanos.

A interação entre os sistemas interno e internacional deve seguir o processo da harmonização considerada mais flexível, ao invés do processo da unificação tido como autoritário e rígido.

A harmonização permite a interação entre distintos elementos cuja equivalência se manifesta no reconhecimento da mesma paramétrica ou dos mesmos valores o que culmina num padrão que visa eliminar ou evitar conflitos. ${ }^{63}$

Por conseguinte, sustenta-se a ideia de centralidade dos direitos humanos como paradigma hermenêutico adequado à problemática que envolve a cooperação jurídica internacional.

Por fim, cabe aduzir que além das questões de cunho político ou econômico, a questão jurídica, em especial, a busca em promover uma harmonização legislativa em matérias fundamentais para o bloco, a exemplo dos acordos de cooperação judiciária, constitui um importante objetivo apto a impulsionar o processo de integração.

\section{CONCLUSÃO}

Como visto, o breve delineamento do panorama geral da cooperação jurídica internacional na atualidade permitiu evidenciar o paulatino desenvolvimento do instituto em comento, bem como de suas modalidades.

Em seus distintos modos, a cooperação internacional tem sido compreendida como toda forma de auxílio entre os Estados e/ou Estados e organismos internacionais, por meio da criação de instrumentos jurídicos internacionais pretende viabilizar alianças, parcerias estratégicas e atividades multilaterais ${ }^{64}$, assim como agilizar a cooperação em geral entre as jurisdições dos diferentes países.

Evidenciou-se que, nesta seara inúmeras questões intrincadas podem se colocar. Assim, a atividade e os mecanismos de cooperação jurídica internacional impõem e demandam empenho considerável na busca em se compatibilizar as soberanias nacionais e a multiplicidade de sistemas ou ordens jurídicas.

Ademais, a cooperação jurídica tem por finalidade promover a cooperação entre os países baseada na outorga de confiança, previsibilidade e segurança jurídica, tendo em vista o

\footnotetext{
${ }^{62}$ Igualdade entre os Estados, não-intervenção, independência nacional, defesa da paz, solução pacífica dos conflitos e cooperação entre os povos.

${ }^{63}$ Evidenciam-se o reconhecimento dos princípios da prevalência da norma mais favorável à cooperação e o princípio da aplicação dos direitos humanos à cooperação jurídica por meio da técnica dos standars como princípios hermenêuticos adequados a promover a harmonização das próprias relações internacionais, tendo em vista que exsurge a relevância da transformação da ideia de mera interação e coexistência rumo à consagração da ideia humanista de cooperação. Em face do primeiro princípio, diante da denegação pelo Estado requerido de atender ato solicitado, tal negativa deve necessariamente ser justificada, posto que o dever de prestação constitui-se a regra e dever internacional. Ademais, decorre ainda deste princípio, que as cláusulas obstativas de cooperação internacional sejam interpretadas restritivamente. O que deve nortear o interprete na solução de eventuais conflitos normativos envolvendo a cooperação jurídica, é o critério da norma mais favorável à cooperação, ressalvada a cláusula da ordem pública internacional. A norma que deverá prevalecer neste tipo de conflito será aquela que melhor propiciar a defesa desse dever internacional que se impõe à ordem interna, ou seja, in dubio pro cooperação. Já o segundo princípio refere-se aplicação à cooperação jurídica internacional da técnica dos direitos humanos como standards normativos. Com vistas a reconhecer os direitos humanos como standard mínimo universal normativo requer-se compreender a forma de interação entre o direito interno e o direito internacional. IENSUE, Geziela; COIMBRA, Luciani. Cooperação Jurídica Internacional e Direitos Humanos: para além da interação rumo à harmonização. São Paulo: Thesis Juris - RTJ, v. 4, n. 3, pp. 521-553, set.-dez., 2015.

${ }^{64}$ Cf. SEITENFUS, R. Manual das organizações internacionais. 4. ed. Porto Alegre: Livraria do Advogado, 2005.
} Revista de Direito Brasileira | São Paulo, SP | v. 16 | n. 7 | p. 428- 444 | Jan./Abr. 2017 
atual contexto de auge da mundialização, e a consequente exponenciação das relações transfronteiriças ou multilocais crescentemente caótica, intrincada e complexa. Entretanto, frisase que se revela fundamental respeitar e promover os direitos humanos dos sujeitos envolvidos em tais pedidos de cooperação.

Procurou-se também destacar a importância da origem e desenvolvimento de um sistema processual de integração no âmbito do MERCOSUL - que apesar de incipiente e construído a partir do modelo clássico do direito internacional - compõem princípios e regras específicas voltadas a imprescindível verticalização do processo de integração, na medida em que impacta os sistemas jurisdicionais de todos os seus Estados Partes.

Ademais, referidos instrumentos jurídicos conformadores desse sistema processual mercosulino, em especial, os mecanismos de cooperação jurídica internacional quando manejados à luz do princípio da dignidade humana, são responsáveis pela garantia e proteção de inúmeros direitos e garantias fundamentais, tais como, o acesso à justiça, a segurança jurídica, o devido processo legal, dentre outros.

Evidencia-se ainda que, a carência de um sistema de justiça sistematizado e uniforme, devido não única e exclusivamente em face da ausência de um Tribunal de Justiça próprio ao MERCOSUL nos mesmos moldes do Tribunal de Justiça da União Europeia. Constituem dessa feita, fatores responsáveis e condicionantes ao avanço do bloco tanto no que tange à harmonização jurídica quanto no que tange ao progresso socioeconômico e político sulamericano.

Por todo o exposto, o presente artigo buscou sustentar também a noção de centralidade dos direitos humanos como um paradigma hermenêutico adequado à problemática que envolve a intrincada operacionalização das distintas formas atuais de cooperação jurídica internacional.

\section{REFERÊNCIAS}

ABADE, Denise. Direitos fundamentais na cooperação jurídica internacional: extradição, assistência jurídica, execução de sentença estrangeira e transferência de presos. São Paulo: Saraiva, 2013.

ACCIOLY, Elizabeth. Um olhar crítico sobre o protocolo de Olivos para solução de controvérsias do MERCOSUL. Temas de Integração. Coimbra: Almedina, n. 19, v. 1, 2005.

ARAÚJO, Nádia. Direito Internacional Privado: teoria e prática. Rio de Janeiro: Renovar, 2007.

A importância da cooperação jurídica internacional para a atuação do Estado brasileiro no plano interno e internacional. In: BRASIL. Ministério da Justiça. Departamento de Recuperação de Ativos e Cooperação Jurídica Internacional, Secretaria Nacional de Justiça. Manual de Cooperação Jurídica Internacional e Recuperação de Ativos: matéria penal, Brasília, 2008.

ARAS, Vladmir. O sistema de cooperação penal Brasil/Estados Unidos. In: BALTAZAR JR., José Paulo; LIMA, Luciano Flores de (Org.). Cooperação Jurídica internacional em matéria penal. Porto Alegre: Verbo Jurídico, 2010.

BECHARA. Fábio Remazzini. Cooperação jurídica internacional em matéria penal: eficácia da prova produzida no exterior. São Paulo: Saraiva, 2011.

CASTELLS, Manuel. Fim de milênio. São Paulo: Paz e Terra, 1999. 
CERVINI, Raul; TAVARES, Juarez. Princípios aplicáveis à cooperação judicial penal internacional no protocolo do Mercosul. Trad. Marcelo Caetano Guazzelli Peruchin. São Paulo: Revista dos Tribunais, 2000.

CHOUKR, Fauzi Hassan. A reforma do CPP e a cooperação jurídica internacional. In: PAGLIARINI, Alexandre Coutinho; CHOUKR, Fauzi Hassan (Coords.). Cooperação Jurídica Internacional. Belo Horizonte: Editora Fórum, 2014.

DELMAS-MARTY, Mireille. Modelos e movimentos de política criminal. Tradução de Edmundo Oliveira. Rio de Janeiro: Revan, 1992.

DREYZIN DE KLOR, A. La primera opinión consultiva en Mercosur:¿gérmen de cuestión predicial? In: Rede. Madri, 2007.

ESPIELL, Héctor Gross. Naturaleza jurídica del Tratado de Asunción y de sus protocolos. In: CHIARELLI, Carlos Alberto Gomes (Coord.). Temas de Integração com enfoques no MERCOSUL. São Paulo: LTr, 1999.

FERRAJOLI, Luigi. Derechos y garantias: la ley del más débil. Madrid: Trotta, 1999. Los fundamentos de los derechos fundamentales. Madrid: Trotta, 2009.

FERNÁNDEZ ARROYO, Diego. Derecho Internacional Privado: una mirada actual sobre sus elementos esenciales. Editora Advocatus. Córdoba: 1998.

FREITAS JR., Antônio de Jesus da Rocha. Manual do MERCOSUL: Globalização e Integração Regional. São Paulo: BH Editora, 2006, p. 310.

GIACOMOLLI, Nereu José; DIETRICH, Eduardo Dalla Rosa. Necessidade e limites na cooperação jurídica internacional em matéria criminal - ordem pública e especialidade. In: PAGLIARINI, Alexandre Coutinho; CHOUKR, Fauzi Hassan (Coords.). Cooperação Jurídica Internacional. Belo Horizonte: Editora Fórum, 2014.

GOMES, Eduardo Biacchi. Manual da Integração Regional. 2. Ed. rev. atual. Curitiba: Juruá, 2015.

IENSUE, Geziela; COIMBRA, Luciani. Cooperação Jurídica Internacional e Direitos Humanos: para além da interação rumo à harmonização. São Paulo: Thesis Juris - RTJ, v. 4, n. 3, pp. 521-553, set.-dez., 2015.

JAYME, Erick. Le droit international prive du nouveau millenaire: la protection de la personne humaine face a la globalisation. In: L'Académie de Droit International de la Haye. Recueil des Cours: Collected Courses of the Hague Academy of International Law. London: Nijhoff, t. 282, Collection, pp. 9-40, 2000.

LIMA, Abili Lázaro Castro de. Globalização econômica, política e direito: análise das mazelas causadas no plano político-jurídico. Porto Alegre: Sergio Antonio Fabris Editor, 2002.

MACHADO. Jónatas E. M. Direito internacional: do paradigma clássico ao pós-11 de setembro. 3. ed. Coimbra: Coimbra Ed., 2006. 
MIRANDA, Jorge. Manual de Direito Constitucional, IV, 5. ed. Coimbra: Coimbra Editora, 2012.

PEREIRA, José Edgard Amorim. A doutrina holandesa “Comitas gentium”. Disponível em: < http://www.direito.ufmg.br/revista/index.php/revista/article/viewFile/685/645> Acesso em: 31 de ago. de 2016.

PEREZ LUÑO, Antonio-Enrique. Los derechos fundamentales. 8. ed. Madrid: Technos, 2004.

PERUCHIN, Marcelo Caetano Guazelli. A proteção dos direitos fundamentais no cenário da cooperação judicial penal internacional. In: PAGLIARINI, Alexandre Coutinho; CHOUKR, Fauzi Hassan (Coords.). Cooperação Jurídica Internacional. Belo Horizonte: Editora Fórum, 2014.

RAMOS, André de Carvalho. A pluralidade das ordens jurídicas e a nova centralidade do Direito Internacional. Boletim da Sociedade Brasileira de Direito Internacional, v. 1, p. 19-45, 2013.

ROBERT, Jacques. Droits de l'homme et libertés fondamentales. 5. ed. Paris: Montchrestien, 1994.

SARLET, Ingo Wolfgang. A eficácia dos direitos fundamentais. 6. Ed. Porto Alegre: Livraria do Advogado, 2006.

SEITENFUS, R. Manual das organizações internacionais. 4. ed. Porto Alegre: Livraria do Advogado, 2005.

VIERIA, Luciane Klein. Interpretación y aplicación uniforme del Derecho de la Integración: Unión Europea, Comunidad Andina y Mercosur. Buenos Aires, Montevideo: Editoria B de f, 2011.

TROTA, Sandro Brescovit. O lugar do crime no Mercosul: as fronteiras da cooperação jurídica internacional contemporânea. Coimbra: Universidade de Coimbra, 2011.

ZAPATERO, Luis Arroyo. A harmonização internacional do Direito Penal: ideias e processos. Revista Brasileira de Ciências Criminais. São Paulo, n. 84, pp.49-76, 2010. 